\title{
Ensino de Antropologia em inglês: reflexões sobre uma experiência de inclusão
}

DOI

http://DX.DOI.ORG/

10.11606/1678-9857.

RA.2020.18968510.11606/16789857.RA.2020.191370

\section{Laura Moutinho}

Universidade de São Paulo, SP, Brasil

https://orcid.org/0000-0001-6479-2711

Imoutinho@usp,br

\section{Rodrigo Brusco}

Universidade de São Paulo, SP, Brasil

https://orcid.org/0000-0002-4672-0770

rrmbrusco@gmail.com

\section{Thais Tiriba}

Universidade de São Paulo, SP, Brasil

https://orcid.org/0000-0002-7438-3724

thaistiriba@gmail.com

RESUMO

PALAVRAS-CHAVE

Neste artigo, apresentamos e refletimos sobre uma iniciativa que conduzimos junto

Ensino de a disciplinas obrigatórias de antropologia na qual oferecemos a alunas e alunos do Bacharelado em Ciências Sociais da Universidade de São Paulo oficinas de capacitação para leitura de textos antropológicos em língua inglesa. Com o amparo da premissa de que é necessário qualificar estudantes para leitura em idiomas estrangeiros, nesse texto, oferecemos, por um lado, um relato de uma experiência docente piloto e, por outro lado, procuramos contribuir para a reflexão sobre o papel da docência no letramento acadêmico de nossas e nossos estudantes. 


\section{INTRODUÇÃO}

Em 2018 e 2019, ingressantes no bacharelado em Ciências Sociais da Universidade de São Paulo participaram de uma iniciativa junto a disciplinas obrigatórias de Antropologia'. Por dois semestres, estudantes frequentaram oficinas de leitura que visavam ampliar seu repertório por meio de capacitação para o acesso a gêneros textuais da nossa disciplina em língua inglesa.

O manejo de idiomas estrangeiros pode abrir muitas possibilidades de trabalho e pesquisa a nossas alunas e alunos. Entretanto, sabemos que as possibilidades de acesso a cursos de língua estrangeira ao longo de suas trajetórias escolares acompanham desigualdades patentes de classe e de raça. Por conta disso, estudantes chegam às salas de aula dos anos iniciais da vida universitária com níveis conhecimentos de língua estrangeira muito díspares.

Da forma como entendemos, há duas maneiras de se lidar com os textos em língua estrangeira nesse contexto. Sensíveis a essa disparidade, docentes podem optar por não colocar nos programas de suas disciplinas artigos em língua estrangeira. Esta tem sido uma maneira democrática de se certificar que os textos serão acessíveis a todas as pessoas. Entretanto, a professora ou professor pode achar imprescindível incluir textos em outros idiomas, via de regra o inglês, e opta por fazê-lo para que estudantes tenham acesso ao debate mais amplo em torno dos tópicos de suas disciplinas. Por vezes, não nos demoramos na questão de se as alunas e alunos, em sua totalidade, irão conseguir acessar esses materiais.

A aprovação tardia de um sistema mais englobante de ações afirmativas na Universidade de São Paulo, que a partir de 2018 faz uso de um sistema de cotas socioeconômicas e raciais para o acesso aos cursos de graduação, torna ainda mais necessária a expansão desse debate que já vem sendo tratado em outros lugares.

Esse é o contexto em que levamos a cabo a iniciativa de oferecer oficinas para capacitação de leitura de textos em inglês. Tratou-se de um projeto que intitulamos "Travessias (im)prováveis: ensino de antropologia em inglês", cuja concepção, desenvolvimento e balanço ora partilhamos. No presente artigo, nosso objetivo é oferecer, por um lado, o relato de uma experiência docente piloto e, por outro lado, uma contribuição para a reflexão sobre o papel da docência no letramento acadêmico de nossas e nossos estudantes.

Iniciamos esta conversa trazendo alguns debates contemporâneos das Ciências Sociais e das Letras que se debruçam sobre a questão da inclusão e do letramento acadêmico. Na sequência, abordamos brevemente a experiência internacional que inspirou a inciativa. Em seguida, partilhamos com as leitoras e leitores a metodologia utilizada bem como reproduzimos as atividades oferecidas e, por fim, trazemos um balanço de toda a experiência pedagógica. 


\section{INCLUSÃO E LETRAMENTO ACADÊMICO}

Como vão apontar muitos trabalhos, a expansão das vagas, abertura de novas universidades e unidades, bem como as políticas de inclusão estão mudando a paisagem do nível superior no Brasil (Neves, 2016; Lima, 2018). Wilson Mesquita de Almeida (2014) investiga o uso dos recursos e espaços da Universidade de São Paulo (USP) por estudantes "com desvantagens econômicas e educacionais". Esse autor oferece um olhar atento às trajetórias estudantis, levando em consideração acesso e permanência, projetando seu olhar para as experiências cotidianas de estudantes.

As grandes cargas - de leitura, de trabalho, de estudo - e o tempo escasso marcam as vivências de alunas e alunos, e fazem parte dos "entraves simbólicos/ formativos" que interferem na apropriação dos conteúdos estudados na universidade. A questão do domínio da linguagem, ou "capital linguístico", é trazida por Almeida (2014) como essencial para o aprendizado das relações existentes nos textos acadêmicos e como alicerce para o aprendizado de idiomas estrangeiros.

Estudantes com quem o autor conversou apontam que um número grande de docentes naturaliza que "alunos e alunas da USP" detenham tais capitais, ao mesmo tempo em que se eximem de ensiná-los metodicamente. Esse é o caso, novamente, do conhecimento e aprendizado de idiomas estrangeiros. Para Almeida e estudantes, docentes da universidade estariam desatentos e desatentas a próprios seus papéis na reprodução dessas desigualdades.

Não apenas nas Ciências Sociais vêm sendo produzidos importantes trabalhos que abordam a urgente necessidade de nos voltarmos ao letramento acadêmico de discentes matriculados na graduação. Marília Mendes Ferreira e Vivian Cristina Rio Stella (2018) argumentam que estudantes da escola regular, ao serem inseridos na comunidade acadêmica, precisam desenvolver e aprimorar habilidades de leitura e escrita. Para essas autoras, a universidade negligencia essa demanda ao assumir que a aluna ou aluno de graduação adquiriu essas habilidades na escola e que essas mesmas habilidades servem para ler e escrever na esfera acadêmica. Elas apontam para a necessidade de se promover o letramento de nível universitário para que estudantes possam ler e produzir textos que atendam às exigências de suas respectivas comunidades científicas. As autoras continuam:

\footnotetext{
Em relação à língua estrangeira, pode-se assumir que o aluno aprendeu a escrever nas aulas dessas línguas, que predominantemente são de cunho geral: inglês geral, francês geral, por exemplo. No Brasil, os cursos mais populares de caráter específico da área acadêmica são de leitura instrumental, que, na atual conjuntura de internacionalização das universidades, apresentam-se bastante defasados. De forma semelhante, do ponto de vista administrativo, essa abordagem deixa o letramento acadêmico sob responsabilidade de escolas de idiomas, professores particulares, tradutores, MOOCS (massive open online courses) mas não da universidade (Ferreira \& Stella, 2018: 21).
} 
Essa abordagem "econômica", como denominam as autoras, exime a universidade de ensinar a escrita e a leitura acadêmicas e a comunidade acadêmica de modo mais amplo segue assumindo que estudantes entram na universidade dominando esses gêneros discursivos ou tendo de "correr atrás do prejuízo". O que essas entre outros e outras autoras argumentam é que tal receita está fadada a fomentar experiências extremamente frustrantes, limitadas e sofridas a futuras pesquisadoras e pesquisadores e profissionais (Ferreira \& Stella, 2018). As autoras, então, sugerem:

A mudança desse quadro requer maior atenção ao ensino do letramento e a criação de uma política de promoção do letramento acadêmico em português e línguas estrangeiras por parte das universidades brasileiras. Acreditamos que a responsabilidade do letramento acadêmico seja tanto do mediador/professor quanto da comunidade discursiva, representada sobretudo pelos docentes de disciplinas e orientadores. A responsabilidade é de ambas as partes que idealmente deveriam trabalhar em conjunto para melhor formação do futuro pesquisador brasileiro em relação a suas habilidades linguísticas e comunicativas.

(Ferreira \& Stella, 2018: 23).

Nossa iniciativa é informada por esses debates que questionam as exigências implícitas de habilidades que a universidade coloca a ingressantes ao mesmo tempo em que se exime de ensiná-las metodicamente. Atentas às necessidades de nossa comunidade científica, e ao papel da docente na formação da próxima geração de antropólogas e antropólogos, buscamos trazer para a sala de aula uma pedagogia da facilitação de acessos e de ensino metódico de ferramentas de leituras e compreensão de textos de nossa disciplina. Além disso, essa experiência didática se alinha ao trabalho de internacionalização das Ciências Sociais que vem sendo conduzido na Faculdade de Filosofia, Letras e Ciências Humanas (FFLCH) da Universidade de São Paulo (USP) e na AUCANI (Agência USP de Cooperação Acadêmica Nacional e Internacional) e visa ampliar o acesso e o envolvimento de estudantes em atividades acadêmicas internacionais. Mais especificamente, essa iniciativa recebeu em 2018 apoio institucional e financeiro da então diretora da FFLCH, a professora Maria Arminda do Nascimento Arruda.

\section{INSPIRAÇÃO}

Essa iniciativa foi inspirada pelas experiências de campo e pesquisa junto a instituições sul-africanas de Laura Moutinho² nas últimas décadas e definida em conversas na própria África do Sul em meio ao trabalho de campo, realizado em 2017, com Thais Tiriba e Pedro Lopes. Podemos tomar como exemplo duas das maiores universidades da África do Sul: a tradicionalmente liberal Witswatersrand, conhecida como Wits e a conservadora Stellenbosch University 3 . São universidades que assumiram
2 | Agradecemos às professoras Fernanda Peixoto e Marina Vanzolini e ao professor Júlio Simões por terem aberto espaço em suas disciplinas para a realização desse projeto-piloto. Detalhes sobre o processo podem ser vistos adiante no item "Oficinas de leitura e discussão de textos de antropologia em inglês".

3 | No momento da realização deste projeto piloto a Faculdade de Filosofia, Letras e Ciências Humanas (FFLCH/ USP) já mantinha dois acordos de cooperação internacional com universidades sulafricanas: a Wits University e a Stellenbosch University, ambos sob coordenação de Laura Moutinho. Recentemente, mais um acordo foi assinado com University of Western Cape, sob coordenação local de Saflate e Moutinho. 
posições opostas no período do regime de segregação. Ambas as universidades vêm sendo, entretanto, pressionadas desde o final do apartheid ${ }^{4}$ a trabalhar de modo mais inclusivo. Muito especialmente, Stellenbosch University manifesta resistência em incorporar o inglês - uma instituição que foi o berço do nacionalismo africânder (Moutinho, 2015) e tradicionalmente ministrava aulas nessa língua.

Brasil e África do Sul ocupam lugares similares em suas regiões: possuem Estado forte, industrializado, com uma estrutura científica que atrai os países do Norte e forma muitos dos mais importantes quadros de outros países do próprio continente africano. Ambos são reconhecidos como economias emergentes e têm força política de destaque sobre outros Estados de seus eixos regionais. Após o fim do regime de segregação, o apartheid, a África do Sul se tornou uma referência no campo jurídico e dos direitos humanos com a Comissão de Verdade e Reconciliação, atraindo cientistas sociais, juristas, filósofas e filósofos do mundo inteiro (Moutinho, 2012). A democracia, entretanto, retém desigualdades e formas de violências persistentes (Matebeni, 2017; Lopes, 2019; Dubbeld, 2021) para as quais a universidade não pode se omitir.

Uma das conhecidas barreiras na África do Sul é o domínio da língua inglesa, num país com atualmente 11 línguas oficiais e que teve o africânder, no passado, como a língua na qual o regime do apartheid dedicou maior atenção em termos de ensino, pesquisa, burocracia e mesmo na vida cotidiana. Muitas pessoas têm o inglês como segunda ou mesmo terceira língua, sendo essa a $4^{a}$ língua mais falada no país, de acordo com o Censo de 2011 (Lopes \& Moutinho, 2012). Nesse sentido, a fluência na língua inglesa implica não somente competência numa língua acadêmica, mas igualmente incorporação à universidade de diferentes com capital linguístico e valores que confrontam as bases coloniais das estruturas universitária, muito especialmente aqueles com very rural background (Borges, 2020).

Ambas as universidades criaram centros de apoio e desenvolvimento da língua inglesa. Algo especialmente investido após a entrada da África do Sul no BRICS5 , em 2010 (em especial no BRICS Network University), e depois de uma série de manifestações pela democratização do ensino, a partir de 2015 (Neves, Moutinho \& Schwarcz, 2019), que ainda mostram sua força de reivindicação. Além disso, há que se mencionar os trabalhos e procedimentos que são adotados em sala de aula. Essas são iniciativas inspiradoras e podem servir como guias para outros contextos que possuem formas similares de desigualdades.

\section{OFICINAS DE LEITURA E DISCUSSÃO DE TEXTOS DE ANTROPOLOGIA EM INGLÊS}

As disciplinas "Antropologia II - Questões de Antropologia Clássica" e "Antropologia IV - Questões de Antropologia Contemporânea" fazem parte do ciclo básico que o corpo discente precisa cursar nos dois primeiros anos de seu bacharelado
4 | Regime autoritário baseado na raça e no racismo, mantido pela força militar, de 1948 a 1994.

5 | BRICS é um acrónimo da língua inglesa (Brasil, Rússia Índia, China e África do Sul) com países do chamado mercado emergente. Ver detalhes em https://www. ipea.gov.br/forumbrics/ptBR/conheca-os-brics.html 
em Ciências Sociais na Universidade de São Paulo. São disciplinas oferecidas no segundo semestre de cada ano letivo.

Nossa iniciativa se deu junto a essas disciplinas no $2^{\circ}$ semestre de $2018 \mathrm{e}$ novamente no $2^{\circ}$ semestre de 2019. Por conta disso, pudemos acompanhar, nesse intervalo, o mesmo grupo de estudantes. Cabe destacar que trabalhamos junto à primeira turma do Bacharelado em Ciências Sociais ${ }^{6}$, cujo ingresso contou com a política de ações afirmativas.

"Antropologia II" tem a proposta ampla de aproximar estudantes da chamada antropologia social britânica bem como da formação da antropologia estadunidense, enquanto "Antropologia IV" procura oferecer algumas das linhas de força da produção antropológica contemporânea. Docentes mantêm, de toda forma, a prerrogativa sobre a seleção dos textos e criação dos programas e os enfoques a serem privilegiados a partir de uma grade básica compartilhada por quem ministra essas disciplinas. O curso é estruturado com aulas expositivas das professoras e professores responsáveis, que são ministradas tendo como base os textos indicados no programa. Frequentemente, mas nem sempre, estudantes de pós-graduação fazem estágio nessas disciplinas através do Programa de Aperfeiçoamento de Ensino (PAE/USP)7.

Diferentemente de iniciativas que focam primordialmente no ensino da língua, o objetivo do nosso projeto foi ampliar o repertório de ingressantes do curso Bacharelado em Ciências Sociais, facilitando o acesso a uma diversidade de gêneros textuais da antropologia que se encontram em língua inglesa, focando, durante as atividades de 2018, em questões clássicas da antropologia, em conexão com a disciplina "Antropologia II" e, nas atividades de 2019, nos debates antropológicos contemporâneos, em conexão com a disciplina "Antropologia IV".

As oficinas seguiram uma dinâmica similar nos dois semestres, com a diferença de que, em 2018 elas, aconteceram no período das aulas e, em 2019, fora dele. $\mathrm{Na}$ primeira experiência, ao fim de um tópico específico do programa, usava-se a segunda metade da aula para trabalharmos com um texto em língua inglesa. Já em 2019, optamos por realizar as oficinas em outro horário. Escolhemos o período das 18:00 às 19:30, o chamado entre-aulas, para tentar acomodar tanto estudantes do vespertino quanto do noturno.

Foram realizadas quatro oficinas em 2018 e quatro oficinas em 2019. De uma atividade para a outra, escutávamos as e os estudantes, e fazíamos ajustes e melhorias. De todo modo, mantivemos ao longo dos dois semestres um mesmo método e um mesmo modelo de atividade. Ele se ancorava, primordialmente, em quatro elementos: (1) questões-guia, (2) uso do próprio texto para a apresentação das ferramentas de leitura, (3) debate permanente em torno das questões de antropologia clássica e contemporânea, e (4) uso de gêneros textuais acadêmicos variados. Antes de compartilhar com as leitoras e leitores algumas sequências didáticas na íntegra, gostaríamos de brevemente comentar sobre esses elementos.

\author{
6|A cada ano ingressam \\ 210 estudantes distribuídos \\ em dois turnos (vespertino \\ e noturno). Cada turno tem \\ uma aula por semana de \\ 4 horas consecutivas. Por \\ causa da grande quantidade \\ de estudantes, as aulas são, \\ em geral, ministradas em \\ pequenos auditórios e temos \\ recursos como microfone, \\ computador e acesso à \\ internet. As disciplinas \\ do ciclo básico são dadas \\ simultaneamente por mais de \\ uma docente. No $2^{\circ}$ semestre \\ de 2018, Antropologia II fo \\ oferecida pelas professoras \\ Fernanda Arêas Peixoto e Laura \\ Moutinho e, no $2^{\circ}$ semestre de \\ 2019, a disciplina Antropologia \\ IV foi oferecida por Júlio Assis \\ Simões e Marina Vanzolini. \\ 7|https://www.prpg.usp. \\ br/pt-br/pae/o-que-pae
}




\title{
PERGUNTAS-GUIA
}

As perguntas-guia eram questões de acesso ao texto antropológico em língua estrangeira. Segue um exemplo das perguntas-guia tiradas de um trecho da atividade 3, realizada no segundo semestre de 2018. Trata-se de uma resenha de Melville ]. Herskovits de Os Nuer publicada em 1944, na American Anthropologist. Segue um trecho. Após ele, em itálico, encontram-se as perguntas-guia desse parágrafo.

\begin{abstract}
The organization of the book is unconventional [...]. At the outset, the place of cattle in the concerns of the Nuer is analyzed, for reasons succinctly given: "Cattle are their dearest possession... Most of their social activities concern cattle and cherchez la vache is the best advice that can be given to those who desire to understand Nuer behavior" (p. 16). We see how cattle determine local and kinship structures, influence thought, play an important economic role, dominate conversation. "Nuer," we learn, "tend to define all social processes and relationships in terms of cattle. Their social idiom is a bovine idiom" (p. 19). [...]
\end{abstract}
A) O que o autor diz sobre a organização do livro?
B) Que razões são sucintamente dadas para a análise do interesse dos Nuer pelo gado [cattle]?
C) O que o gado determina? O que ele influencia? Em que área tem papel importante? O que domina?
D) O que os Nuer tendem a definir em relação ao gado? Como é idioma social Nuer?

As perguntas são elaboradas para possibilitar o acesso ao texto para estudantes que tenham pouco ou nenhum conhecimento do idioma estrangeiro. A formulação das perguntas, usando cognatos das palavras em inglês e fazendo uso dos mesmos termos do texto, é feita de tal forma que as alunas e alunos possam com mais facilidade localizar as respostas e já tenham acesso às ideias gerais do artigo. Em vez de se depararem com o texto e dizerem "não entendo nada!", como um número grande de estudantes nos disse ser sua reação costumaz diante de textos em inglês, as perguntas ajudam a ultrapassar a primeira barreira, na qual recusa e ininteligibilidade se misturam e afastam a possibilidade de aprendizagem.

\section{APRESENTAÇÃO DAS FERRAMENTAS DE LEITURA}

Além do acesso ao texto pelas perguntas-guia, também oferecíamos ferramentas de leitura para que pudessem ir desenvolvendo suas habilidades ${ }^{8}$. Essas ferramentas eram apresentadas a alunas e alunos e praticadas junto ao texto a ser trabalhado em cada sessão. Damos um exemplo: na atividade acima mencionada trabalhamos o tópico linguístico de processos de formação de palavras. Notem que algumas palavras do

8 | Para a apresentação dos tópicos linguísticos e elaboração dos exercícios fizemos amplo uso do Manual de Inglês Instrumental da Universidade Estadual de Santa Cruz/BA (NETTO, 2012). trecho reproduzido estão em negrito. Depois de apresentar os diferentes processos de 
formação de palavras em inglês, propomos um exercício em dupla, no qual deveriam identificar os processos utilizados na formação de cada termo em negrito.

\section{USO DE GÊNEROS TEXTUAIS VARIADOS E PARALELOS COM AS DISCIPLINAS}

O uso do próprio texto para a prática do instrumental de leitura, ao lado do uso de diferentes gêneros textuais em inglês, foram fundamentais no nosso propósito de ampliar o debate em torno das questões trabalhadas em "Antropologia II" e "Antropologia IV". Ao longo dos dois semestres, fizemos uso de resenhas, verbetes biográficos, verbetes temáticos, entrevistas e, na última atividade, de um artigo propriamente dito. Esses textos eram cuidadosamente selecionados de maneira a manterem um diálogo direto com os textos clássicos e assuntos tratados em cada momento de Antropologia Il e Antropologia IV em que a oficina fosse ocorrer. A maior parte das e dos estudantes não tinha ainda familiaridade com esses gêneros textuais nem com seu potencial para estudo e pesquisa no campo antropológico. Dessa forma, o trabalho com esses textos era também um trabalho de aproximação de alunas e alunos a essa variedade de gêneros acadêmicos.

A elaboração da metodologia de trabalho e das atividades foi realizada por Thais Henriques Tiriba, discutida com a professora Laura Moutinho, que coordenou todo o processo pedagógico e institucional, e contou com o apoio de Rodrigo Rossi Mora Brusco na segunda fase de atividades. Em 2018, as oficinas foram comandadas por Thais e, em 2019, por Thais e Rodrigo.

Thais Henriques Tiriba e Rodrigo Rossi Mora Brusco são doutorandos do Programa de Pós-Graduação em Antropologia Social da Universidade de São Paulo (PPGAS/USP) e realizaram nessa instituição toda sua formação. Ambos têm formação no ensino de inglês e trabalharam como professores do idioma antes de ingressarem na pós-graduação. Nos semestres em que foram realizadas essas experiências didáticas, Thais e Rodrigo participavam ainda do programa de estágio para docência (PAE/USP) nas disciplinas em questão. Thais pesquisa relações raciais, sexualidade e de gênero no Brasil e África do Sul (Tiriba, 2019) e Rodrigo tem seu olhar voltado para etnologia indígena. Em 2018, Thais recebeu apoio financeiro da diretoria da FFLCH para preparar e conduzir as aulas. Em 2019, Thais e Rodrigo trabalharam de maneira voluntária trabalhando com a perspectiva de consolidar o programa através de uma política de apoio de bolsas de monitoria.

\section{SEQUÊNCIA DIDÁTICA}

A seguir reproduzimos na íntegra um dos planos de aula, referente à segunda sessão da oficina, oferecida nos dias 15 e 16 de outubro de 2018. O plano de aula de cada atividade servia de guia para o oferecimento de cada sessão. Ele era debatido entre nós antes de ser finalizado. Cada plano de aula contém, além do título e data de seu oferecimento, a referência do texto a ser trabalhado, as leituras já trabalhadas em sala com a turma, os 
objetivos da atividade e a sequência didática. O plano de aula era de uso da coordenadora e monitora e monitor. Aos alunos e alunas era dado uma folhinha de trabalho onde constava o texto a ser trabalhado, as perguntas-guia e as atividades de capacitação para leitura.

PLANO DEAULA

\section{Plano de aula: Atividade 2-Escola de Manchester e marcadores de discurso} 15 e 16 de outubro de 2018

Material original: Max Gluckman. In: Biographical Dictionary of Social and Cultural Anthropology. Vered Amit (Org). New York: Routledge, 2004

\section{Leituras pertinentes já realizadas pela turma:}

GLUCKMAN, Max. "Análise de uma situação social na Zululândia moderna”.

MITCHELL, J. Clyde. "A dança kalela: aspectos das relações sociais entre africanos urbanizados na Rodésia do Norte".

Objetivos da atividade: (1) Apresentar o gênero verbete; (2) Apresentar ferramentas para reconhecerem Marcadores de Discurso em textos de língua inglesa; (3) Fechar o conjunto de aulas sobre a Escola de Manchester trazendo um sumário de suas contribuições analítico-metodológicas.

\section{PASSO A PASSO DA ATIVIDADE}

Iniciamos a atividade trazendo novamente os tópicos da atividade anterior (Atividade 1): inferir significado a palavras desconhecidas por meio de nossos conhecimentos de mundo e conhecimentos linguísticos.

Apresentamos, então, o gênero a ser trabalhado na atividade 2 , o verbete. Trata-se, apresentamos, de uma maneira de trabalhar um conceito de forma sucinta, sistemática e objetiva. Diferentes áreas do conhecimento têm seus próprios dicionários e enciclopédias de verbetes.

Usamos essa oportunidade para trazer à turma a EA, Enciclopédia de Antropologia ${ }^{9}$ produzida pelo Departamento de Antropologia da Universidade de São Paulo. Projetamos seu site e fizemos algumas buscas a temas que diziam respeito ao programa a ser trabalhado na disciplina como um todo.

Apresentamos outras enciclopédias antropológicas online, como a da Universidade de Cambridge, e navegamos pela gama de verbetes disponíveis, apontando para a importância e utilidade desse gênero acadêmico.

Apresentamos, em seguida, o dicionário de verbetes biográficos onde se encontra o verbete que trabalharíamos em aula. Em seguida, navegamos por outros verbetes potencialmente úteis a alunas e alunos que diziam respeito à disciplina.

Mostramos à turma a estrutura do verbete a ser trabalhado. Ele se inicia com o nome da autora ou autor, anos de nascimento e morte, alguns parágrafos de texto 
sobre sua vida e atuação no campo da disciplina, instituições onde estudou, lugares onde fez campo e suas publicações chave.

A partir desse momento, passamos a fazer uso da folhinha de atividades em que a turma pudesse já ter acesso ao texto trabalhado, ao glossário e às perguntas-guia. Reproduzimos a seguir o primeiro parágrafo da folhinha de atividade:

\section{Gluckman, Max}

b. 26 January 1911, Johannesburg, South Africa

d. 13 April 1975, Jerusalem, Israel

As a scholar, teacher, and organiser of research, Max Gluckman made vital contributions to social, political, and legal anthropology from the 1940 s to his death in 1975. His early fieldwork in South Africa during the late 1930s led to seminal articles that, while rooted in then dominant structural-functionalist concerns about pre-contact tribal societies and social equilibrium, nonetheless addressed the impact of colonisation and white settlement ( )/( )/ ( ). In African Political Systems (1940), only contributions by Audrey Richards and Gluckman (in his chapter on the Zulu Kingdom) included sections on European rule and post-European changes. In 'Analysis of a social situation in modern Zululand' (1940), he developed the concept of the social situation, in this case a bridge-opening ceremony, as an observed event from which anthropologists abstract social structure, relationships, and institutions of a particular society. Moreover, by positing 'the existence of a single African-White community', Gluckman foreshadowed a major preoccupation of the Rhodes-Livingstone Institute (RLI) anthropologists as well as the later anthropology of colonialism ( )/( ). He noted, for example, that the Zulu desire for European material goods and the European need for Zulu labour and wealth brought these two groups together in a situation of both interdependence and conflict ( )/( ).

a) Max Gluckman contribuiu para que áreas do conhecimento antropológico?

b) Para o que seus artigos baseados no trabalho de campo na África do Sul no fim da década de 1930 chamavam a atenção?

c) Qual o conceito desenvolvido por Gluckman em "Análise de uma situação social na Zululândia moderna" e o que poderia ser abstraído daí?

d) Que questões Gluckman antecipa, ao postular a existência em uma única comunidade African-White?

Constantemente, lembrávamos a turma de que as perguntas eram simples e continham os cognatos que facilitariam a localização das respostas. Também experimentamos com uma outra forma de estruturar o glossário. Selecionamos as palavras cujos significados poderiam ser mais complicados de inferir e colocamos sua classe gramatical e definição em inglês como nota de rodapé. Trata-se de uma 
maneira de apresentar a turma o uso de dicionários monolíngues e lembrar o corpo discente de que seu uso é de grande importância e pode servir para a ampliação de vocabulário. De todo modo, mantivemos uma tradução dos termos entre colchetes logo depois das definições em inglês.

Abrimos o dicionário Cambridge online para uso de falantes de português do Brasil, de onde haviam sido tiradas as definições, e mostramos à turma de que formas usar essa importante ferramenta.

Solicitamos que fizesse a primeira passagem pelo texto localizando as respostas para as questões. Chamamos novamente sua a atenção aos cognatos e à ativação seus conhecimentos prévios, tanto linguísticos quanto de mundo, e de tudo o que já vinham aprendendo sobre a Escola de Manchester. Solicitamos que lessem as perguntas antes de passar pelos parágrafos, que atentassem ao uso do glossário e que nos chamassem caso tivessem quaisquer questões.

Dado o tempo de uma primeira passagem pelo texto, localizamos juntos as respostas no texto usando o projetor. As respostas eram colocadas em inglês e depois apresentada a tradução de cada frase. Desse modo, o conjunto de estudantes tinha acesso ao conteúdo completo do verbete. Aproveitamos esse momento para tirar dúvidas também sobre o conteúdo do texto e sua relação com as leituras já realizadas na disciplina.

Terminada essa primeira etapa, passamos para o tópico linguístico da atividade. Apresentamos a estudantes os marcadores de discurso, ou conectivos: palavras ou conjuntos de palavras de extrema importância para quem está desenvolvendo habilidades de leitura e compreensão de texto. Os marcadores indicam a relação estabelecida entre duas frases e falam muito sobre a intenção das autoras e autores dos textos. São palavras, normalmente conjunções, usadas para ligar orações e ideias no texto. Reconhecer e, eventualmente, usar os conectivos é fundamental para decodificar as ideias do texto. Além do mais, a escolha dos marcadores mais pertinentes pode dar ao texto coesão e elegância (Netto, 2012).

Apresentamos a alunos e alunas alguns tipos de marcadores de discurso, focando em suas diferentes funções no texto, como contraste, consequência, adição e exemplificação (vide Netto, 2012, p. 186 e 187).

No verbete impresso que a turma recebeu, destacamos alguns marcadores por parágrafo. No final das frases em que estavam contidos, deixamos um parênteses em negrito [()] para que completassem a seguinte atividade: estudantes deviam, após cada marcador, deixar registrado se tratava-se de um marcador de adição [marcar $\mathrm{A}]$, de contraste [marcar C] ou de exemplificação [marcar E]. Solicitamos que fizessem essa atividade em duplas.

Tratava-se de uma maneira de já decifrar os tipos de marcadores por si, ao mesmo tempo em que pensavam na estrutura do texto e passavam mais uma vez por 
seu conteúdo. Passado o tempo da atividade nos voltamos à projeção e recolhemos as respostas de alunas e alunos

\section{BALANÇO DA INICIATIVA E CONSIDERAÇÕES FINAIS}

No decorrer da primeira fase, em 2018, ouvimos de alunos e alunas suas impressões ao longo de todo o semestre. Tivemos dois momentos explícitos, o primeiro, após a segunda atividade e o segundo, depois da avaliação. De toda forma, estudantes vinham até nós deixar seus comentários e sugestões a respeito das atividades. Algumas dessas sugestões pudemos incorporar às atividades seguintes. Em 2019, optamos por circular um pequeno questionário de avaliação ao fim do semestre. Nesse ano, contamos também com a presença de estudantes de mestrado do Programa de Pós-Graduação em Antropologia Social (PPGAS/USP) que, com interesse pelas possibilidades de aprimoramento de suas ferramentas de leitura em inglês, participaram das sessões com alunas e alunos de graduação.

O retorno da turma, nas duas ocasiões, foi bastante positivo. Tivemos estudantes que relataram pensar não ter conhecimentos de inglês suficientes para levar a cabo as atividades, e sentiram surpresa e satisfação em conseguir fazê-lo. Falaram que tinham conhecimento "nulo" do idioma, ou disseram que aprenderam muito pouco na escola. Sentiam-se em "defasagem". De todo modo, disseram ter gostado das atividades, pois as perguntas que guiavam as passagens pelo texto permitiam um primeiro acesso facilitado. Escutamos de participantes que as atividades serviram de encorajamento a seguir trabalhando com os textos e a "perder o medo".

Estudantes que possuíam maiores conhecimentos linguísticos no idioma estrangeiro, disseram ter achado positivo o trabalho com outros gêneros discursivos acadêmicos em inglês. As apresentações desses outros tipos de textos e as ferramentas de busca por resenhas, dicionários de verbetes, dicionários monolíngues, etc. trazidos por nós foram lidas como positivas. Também consideraram especialmente boa a oportunidade de revisitar e ampliar o conteúdo visto na disciplina e acharam que voltar aos textos em inglês usados nas atividades "foi bom para estudar para a prova". As críticas recebidas lamentavam o tempo curto das oficinas e pediam maior periodicidade. O feedback positivo nos anima, pois nossa impressão também é a de que a experiência didática teve sucesso e deve ser aprimorada e estendida.

Nossa iniciativa, sabemos, não substitui o aprendizado contínuo do idioma estrangeiro nem os cursos de idioma regulares. Ao longo das atividades, incentivamos estudantes a buscarem os cursos de inglês gratuitos e de baixo custo oferecidos em algumas unidades da Universidade. Muitos e muitas o fizeram e algumas pessoas disseram tê-lo feito depois de ter se deparado com a possibilidade 
de acessar os conteúdos em inglês que oferecemos nas atividades. "Ler um texto em inglês pela primeira vez de verdade", como experenciado por parte da turma em nossas atividades, pode servir de incentivo para desmontar barreiras no aprendizado de idiomas estrangeiros que, como apontamos na introdução, por vezes caminham ao lado das desigualdades raciais e classe. Assim, nossa experiência em oferecer ferramentas de leitura e de decodificação de textos a estudantes em sua fase inicial de formação, promovendo o acesso a conteúdos de nossa disciplina em inglês, mostrou-se uma forma frutífera, cuidadosa e, na nossa leitura, democrática, de contribuir para uma importante conversa sobre as relações entre o papel da docência nas disciplinas obrigatórias de Antropologia e o letramento acadêmico de nossas alunas e alunos. Essa iniciativa, no momento, está sendo desenvolvida exclusivamente entre discentes do Programa de Pós-Craduação em Antropologia Social (PPGAS/USP) e conta com cerca de 20 estudantes $^{10}$. O compartilhamento desse processo será feito em nossa próxima conversa.

Laura Moutinho é professora Associada (Livre-Docente) do Departamento de Antropologia e coordenadora do PPGAS, ambos da USP. Pesquisadora do Núcleo de Estudos sobre Marcadores Sociais da Diferença (NUMAS/USP). Coordena a Comissão Editorial de Periódicos Científicos (ABA) e o Comitê Estudos Africanos (ABA). Coordena 3 acordos de cooperação internacional com universidades sul-africanas: FFLCH/USP e a Wits University, Stellenbosch University e a University of Western Cape. É bolsista produtividade e coordena projeto contemplado no Edital Universal, ambos do CNPq e tem apoio da Fapesp.

Thais Tiriba é Doutoranda em Antropologia Social (PPCAS/ USP), com financiamento da FAPESP (Processo:19/01498-9). Mestra em Antropologia Social pela mesma instituição (PPGAS/USP 2016). Possui bacharelado (2013) e licenciatura (2019) em Ciências Sociais também pela Universidade de São Paulo. Pesquisadora do Núcleo de Estudos sobre Marcadores Sociais da Diferença (NUMAS/USP). Desenvolve pesquisas na área de relações de gênero, relações raciais, mercados matrimoniais transnacionais e conjugalidades contemporâneas no Brasil, Alemanha e África do Sul.

Rodrigo Brusco é Bacharel em Ciências Sociais pela Universidade de São Paulo. É mestre em Antropologia Social pelo PPCAS/USP e doutorando na mesma instituição, além de Sócio Colaborador da Comissão Pró-Índio de São Paulo (CPI-SP). Desde 2018 realiza pesquisa etnográfica junto ao povo Kawaiwete do Xingu. Tem interesse e atua na área de Antropologia, nos temas: etnologia indígena, transformação indígena,
10| O PPCAS/USP vem conduzindo uma série de iniciativas com o objetivo de avaliar as políticas de inclusão que vêm sendo conduzidas pelo Programa. Parte desse processo de diálogo pode ser visto no Canal do PPCAS no YouTube. Pelo potencial reflexivo, chamamos atenção para o Seminário "Ações afirmativas na Pós-Graduação: reflexões e desafios", realizado em parceria com a Comissão Permanente de Ações Afirmativas (COPAF) e o Programa de Pós-Graduação em Sociologia (PPCS), nos dias 30/09 e 01/10 de 2021. https:// www.youtube.com/channel/ UC-pjHB5 C $_{3}$ VT1uuy6OhOpUiQ 
parentesco e teoria antropológica. Seu doutoramento é realizado com financiamento da FAPESP (Processo:19/00170-0).

Contribuições de autoria: Não se aplica

FINANCIAMENTO: O projeto teve apoio financeiro da Diretoria da FFLCH, em 2018. Contou também com suporte do CNPq, FAPESP e de bolsa do Programa de Aperfeiçoamento de Ensino (PAE/USP).

\section{REFERÊNCIAS BIBLIOGRÁFICAS}

ALMEIDA, Wilson Mesquita de. 2014. Estudantes com desvantagens sociais e os desafios da permanência na universidade pública. PIOTTO, Débora C. (Org.). Camadas populares e universidades públicas. Trajetórias e experiências escolares. São Carlos: Pedro \& João Editores.

BORGES, Antonádia. 2020. Very rural background: os desafios da composiçãoterra da África do Sul e do Zimbábue à chamada educação superior. Revista de Antropologia, 63(3), e178183. https://doi. org/10.11606/1678-9857.ra.2020.178183

AMIT, Vered. 2004. Biographical Dictionary of Social and Cultural Anthropology. New York: Routledge.

DUBBELD, Bernard. 2021. Granting the Future? The Temporality of Cash Transfers in the South African Countryside. Revista de Antropologia, 64(2), e186648. https://doi. org/10.11606/1678-9857.ra.2021.186648

FERREIRA, Marília Mendes; STELLA, Vivian Cristina Rio. 2018. Redação acadêmica: múltiplos olhares para o ensino da escrita acadêmica em português e línguas estrangeiras. São Paulo: FFLCH Humanitas.

HERSKOVITS, Melville ]. 1944. Review of The Nuer: a Description of the Modes of
Livelihood and Political Institutions of a Nilotic People" by E. E. Evans-Pritchard. American Anthropologist (46), issue 3, 396/400 https:// doi.org/10.1525/aa.1944.46.3.02a00160

LIMA, Marcia. 2018. A produção de conhecimento em tempos de conflito: o lugar das Ciências Sociais. Revista de Antropologia, 61(1), 95-102. https://doi. org/10.11606/2179-0892.ra.2018.145516 LOPES, Pedro \& MOUTINHO, Laura. 2012. Uma Nação de Onze Línguas? Diversidade social e linguística nas novas configurações de poder na África do Sul. Tomo (UFS), v. 20, p. 27-57. https://doi.org/10.21669/tomo.voi20.859

LOPES, Pedro. 2019. Deficiência como categoria do Sul Global: primeiras aproximações com a África do Sul. Revista Estudos Feministas, v. 27, p. e66923. https:// doi.org/10.1590/1806-9584-2019v27n366923

MATEBENI, Zethu. 2017. Perspectivas do Sul sobre relações de gênero e sexualidades: uma intervenção queer. Revista de Antropologia, 60(3), 26-44. https://doi. org/10.11606/2179-0892.ra.2017.141826

MOUTINHO, Laura. 2015. On The other side? Das implicações morais de certos horizontes imaginativos na África do Sul. Anuário Antropológico, v. 40, p. 77-97, 2015. 
Artigo | Laura Moutinho, Thais Tiriba, Rodrigo Brusco | Ensino de Antropologia em inglês:

reflexões sobre uma experiência de inclusão

MOUTINHO, Laura. 2004. Razão, "Cor"

e Desejo: Uma Análise Comparativa

sobre Relacionamentos Afetivo-Sexuais

"inter-raciais" no Brasil e na África do

Sul. São Paulo: UNESP. 450p

MOUTINHO, Laura. 2012. Sobre danos, dores e reparações: The Moral Regenaration Movement-controvérsias morais e tensões religiosas na ordem democrática sulafricana. In: TRAJANO FILHO, Wilson. (Org.). Travessias antropológicas: estudos em contextos africanos. 1ed.Brasília: ABA, pp. 10-36.

NETTO, Lucia Regina Fonseca. 2012. Inglês Instrumental. Ilhéus: Editora da UESC, 2012.

NEVES, Paulo S. C; FARO, André \&

SCHMITZ, Heike. (2016). As ações

afirmativas na Universidade Federal de Sergipe e o reconhecimento social: a face oculta das avaliações. Ensaio: Avaliação e Políticas

Públicas em Educação, 24(90), 127-160. https://

dx.doi.org/10.1590/S0104-40362016000100006

NEVES, Paulo Sérgio da Costa, MOUTINHO, Laura \& SCHWARCZ, Lilia. 2019. Herança colonial confrontada: reflexões sobre África do Sul, Brasil e Estados Unidos. Revista Estudos Feministas, v. 27, p. e66960-e66960. https:// doi.org/10.1590/1806-9584-2019v27n366960

TIRIBA, Thais Henriques. 2019. Sugar relationships: sexo, afeto e consumo na África do Sul e no Brasil. Revista Estudos Feministas, v. 27, p. e66921. https://doi. org/10.1590/1806-9584-2019v27n366921

Recebido em 1 de setembro de 2021. Aceito em 13 de outubro de 2021. 